\title{
Hubungan Self-control dengan Online Gaming Addiction pada Mahasiswa di Surabaya
}

WIRA ADI CAHYO WIBOWO \& AFIF KURNIAWAN*

Departemen Psikologi Klinis dan Kesehatan Mental, Fakultas Psikologi Universitas Airlangga

\begin{abstract}
ABSTRAK
Penelitian ini bertujuan untuk mengetahui hubungan antara self-control dengan online gaming addiction pada mahasiswa di Surabaya. Self-control merupakan kemampuan individu untuk menolak atau mengubah suatu respon untuk menyela perilaku yang tidak diinginkan dengan menahan diri dari melakukan hal tersebut. Online gaming addiction adalah suatu perilaku kompulsif dalam memainkan game online demi mendapat kepuasan tersendiri. Penelitian ini melibatkan 116 mahasiswa di Surabaya, dengan rentang usia 18-21 tahun. Alat pengumpul data berupa kuesioner self-control scale (SCS) dan alat ukur gaming addiction scale (GAS). Analisis data dilakukan dengan teknik statistik korelasi Pearson $r$, dengan bantuan program JAMOVI VERSION 1.6. Hasil analisis data penelitian diperoleh nilai korelasi antara self-control dengan online gaming addiction sebesar -0.388 dengan p sebesar <.001. Hal ini menunjukkan bahwa terdapat hubungan dengan tingkat korelasi yang sedang dan negatif antara selfcontrol dengan online gaming addiction.
\end{abstract}

Kata kunci: mahasiswa di Surabaya, online gaming addiction, self-control

\begin{abstract}
This study aims to determine the relationship between self-control and online gaming addiction among students in Surabaya. Self-control is individual's ability to reject or change response to interrupt unwanted behavior by refraining from doing so. Online gaming addiction is a compulsive behavior in playing online games for the sake of personal satisfaction. This study involved 116 students in Surabaya, with age range of 18-21 years. Data collection tools are form of a self-control scale (SCS) questionnaire and gaming addiction scale (GAS) measuring instrument. Data analysis using Pearson r correlation technique with JAMOVI VERSION 1.6 program. The results of the data analysis showed that the correlation value between self-control and online gaming addiction was -0.388 with $\mathrm{p}<.001$. This shows that there is a relationship with moderate and negative correlation level between self-control and online gaming addiction.
\end{abstract}

Keywords: college student in Surabaya, online gaming addiction, self-control

Buletin Penelitian Psikologi dan Kesehatan Mental (BRPKM), 2021, Vol. 1(1), 78-86

*Alamat korespondensi: Fakultas Psikologi Universitas Airlangga, Kampus B Universitas Airlangga Jalan

Airlangga 4-6 Surabaya 60286. Surel: afif.kurniawan@psikologi.unair.ac.id

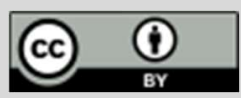

Naskah ini merupakan naskah dengan akses terbuka dibawah ketentuan the Creative Common Attribution License (CC-BY-4.0) (http://creativecommons.org/licenses/by/4.0), sehingga penggunaan, distribusi, reproduksi dalam media apapun atas artikel ini tidak dibatasi, selama sumber aslinya disitir dengan baik. 


\section{P E N D A H U L U A N}

Masa perkuliahan merupakan salah satu masa yang pada umumnya dilalui oleh setiap manusia, kemudian dalam dunia perkuliahan terdapat istilah mahasiswa. Menurut Daldiyono (2009) mahasiswa adalah seseorang yang telah lulus dari sekolah lanjutan tingkat atas dan sedang menempuh pendidikan tinggi. Seseorang yang sedang menempuh masa perkuliahan di Indonesia biasanya berusia 17 hingga 25 tahun, dimana pada usia tersebut, seseorang sedang melalui tahap remaja dan terjadi peralihan dari masa remaja akhir menuju dewasa awal. Tugas pokok mahasiswa adalah belajar secara total sesuai dengan bidang ilmu yang dipilih guna menyelesaikan studinya (Daldiyono, 2009). Namun, pada kenyataannya seringkali mahasiswa tidak fokus untuk menyelesaikan tugas pokoknya melainkan melakukan kegiatan lain di luar perkuliahan, salah satu contoh dari kegiatan lain tersebut adalah bermain game online. Game online merupakan situs yang menyediakan berbagai jenis permainan yang melibatkan beberapa pengguna internet di berbagai tempat yang berbeda untuk saling terhubung bermain game di waktu yang sama dan mengunduh berbagai macam konten game baru melalui jaringan wireless internet (Rooij, 2011).

Tujuan awal dari diciptakannya game online adalah sebagai media untuk menghilangkan penat, dan game online juga menyediakan lingkungan virtual dimana para pemainnya dapat bersenang-senang dan leluasa menggunakan identitas yang berbeda dengan kehidupan nyatanya, berbicara bahasa lain, dan membentuk hubungan sosial baru dengan orang yang belum pernah mereka temui pada kehidupan 'nyata'. Namun, game online telah mengakibatkan ketagihan pada hampir semua pemakainya (Young, 2009).

Berdasarkan studi yang dilakukan oleh Pokkt, Decision Lab dan Mobile Marketing Association (MMA) pada tahun 2017, jumlah pemain game khususnya game mobile di Indonesia mencapai 60 juta dan jumlah tersebut diperkirakan akan meningkat menjadi 100 juta pada 2020. Hasil studi menunjukkan, mayoritas aktivitas yang dilakukan masyarakat melalui smartphone yaitu bermain game (25\%). Mereka rata-rata bermain game mobile dengan durasi 53 menit. Ditinjau dari sisi usia menunjukkan bahwa seperempat dari jumlah total pemain game online memiliki usia 16-24 tahun dan 25-34 tahun, dimana persentasenya masing-masing 27\%. 24\% lainnya tercatat berusia 35-44 tahun. Pengguna smartphone dengan usia 45-54 tahun juga turut aktif memainkan game mobile dengan persentase 17\% dari basis pemain game di Indonesia (Maulida, 2018). Kecanduan bermain game online memiliki dampak yang cukup serius, yaitu dapat membuat individu melakukan kegiatan kriminal seperti mencuri demi mendapatkan uang untuk bermain game online. World Health Organization (WHO) memasukkan kecanduan game ke dalam daftar penyakit dalam laporan International Classification of Diseases edisi 11 (ICD-11). Dengan demikian kecanduan game atau Online Gaming Addiction resmi masuk sebagai gangguan kesehatan jiwa.

Berdasarkan riset yang dilakukan oleh Lenovo, rata-rata pemain game online menghabiskan 7,5 jam per minggu untuk bermain game, dengan 28\% pemain bermain lebih dari 10 jam tiap minggunya (Marketeers, 2019). Kemudian, menurut survei Enciety Business Consult (EBC) menyebutkan bahwa rata-rata pemain game online di kota Surabaya menghabiskan waktu bermain game online sekitar 2-8 jam sehari bahkan pada hari libur dapat bermain game online hingga lebih dari 8 jam sehari (Antara Jatim, 2018). Berkembangnya pusat game di kota-kota besar maupun kecil berdampak pada meningkatnya jumlah pemain game online di suatu kota. Warkop atau warung kopi kini juga menjadi pusat game atau tempat untuk bermain game online, tak hanya menyediakan minuman, warkop juga menyediakan koneksi internet untuk bermain game online. Dikutip dari detiknews pada tahun 2018, "banyak warung kopi yang tersedia di sudut-sudut kota Surabaya yang digunakan oleh pelajar maupun mahasiswa untuk bermain game online, mereka betah berjam-jam disana untuk bermain game, paling 
sedikit 2-3 jam" (detiknews, 2018). Hasil penelitian yang dilakukan oleh Rosiana (2019) menyebutkan bahwa remaja di Surabaya bermain game online untuk mencapai tujuan prestasi dan mencari aitemaitem langka dalam game tersebut, mencari rekan dalam sebuah game dan bergabung dalam komunitas, berlatih untuk mengikuti turnamen suatu game online atau bekerja sebagai joki dalam suatu game online. Hal tersebut menandakan bahwa game online kini tidak hanya sebagai media untuk menghilangkan penat saja, melainkan banyak tujuan-tujuan lain individu dalam bermain game online. Namun, game online juga dapat memberikan efek ketagihan bagi para penggunanya.

Sifat game online yang dapat memberikan efek ketagihan bagi para penggunanya yang membuat mereka tidak dapat mengontrol keinginan untuk bermain sehingga menyebabkan tingginya intensitas bermain game online. Hal ini akan berdampak dan berakibat buruk bagi mereka. Ismail dan Zawahreh (2017) mengatakan bahwa kecanduan internet dan game online menyebabkan hilangnya kontrol, penarikan, pelemahan fungsi, dan ketidakmampuan pengambilan keputusan, sebuah pengalaman, kecemasan, gairah dan kegembiraan psikomotor dan agresi. Kecanduan game online pada mahasiswa dapat berdampak bagi kesehatan mental, memburuknya kondisi finansial dan kurangnya kontrol diri atau selfcontrol. Self-control menurut Tangney dkk. (2004) adalah kemampuan individu untuk menolak atau mengubah suatu respon, serta untuk menyela perilaku yang tidak diinginkan dengan menahan diri dari melakukan hal tersebut. Online Gaming Addiction atau kecanduan bermain game online adalah perilaku seseorang yang ingin terus bermain game online dan tidak dapat dikontrol atau tidak mempunyai kekuatan dalam mengehentikannya (Young, 2009).

Hasil penelitian yang dilakukan oleh Teng, Li dan Liu (2014) menunjukkan adanya korelasi antara agresivitas, kecanduan internet, dan game online, dengan self-control yang rendah di kalangan siswa. Selanjutnya, penelitian yang dilakukan oleh Mehroof \& Griffith (2010) yang melibatkan 123 mahasiswa East Midlands University di Inggris, menunjukkan bahwa terdapat hubungan yang signifikan antara lima sifat (neurotisisme, mencari sensasi, ciri kecemasan, self-control, dan agresi) dengan kecanduan game online. Penelitian lain yang dilakukan oleh Chen dan Chang (2008) menunjukkan bahwa berdasarkan analisis korelasi kanonik, variabel estetika, karakter dan interaksi sangat berkaitan dengan aspek-aspek dalam variable kecanduan game online, yaitu withdrawal dan tolerance. Chen dan Chang (2008) menemukan bahwa para pemain game online didominasi oleh laki-laki remaja dan laki-laki dewasa yang berusia diatas tiga puluh tahun.

Faktor-faktor yang menyebabkan terjadinya kecanduan bermain game online terbagi menjadi 2 yaitu faktor internal dan faktor eksternal. Faktor internal diantaranya adalah rasa bosan yang dirasakan ketika berada dirumah atau dikampus, ketidakmampuan mengatur prioritas, kurangnya kontrol diri atau self-control dalam diri individu dan keinginan yang kuat dalam mendapatkan nilai tinggi dalam suatu permainan. Faktor eksternalnya adalah kurang memiliki hubungan sosial yang baik, sehingga remaja memiliki alternatif bermain game online sebagai aktivitas yang menyenangkan (Puspita \& Mulyana, 2018).

Self-control pada satu individu dengan individu lain tidaklah sama, terdapat individu yang memiliki selfcontrol yang tinggi, namun terdapat juga individu yang memiliki self-control rendah. Apabila dikaitkan dengan mahasiswa, mahasiswa yang mempunyai self-control yang rendah akan mengalami kesulitan dalam mengatur dan mengarahkan perilakunya, sedangkan mahasiswa yang memiliki self-control yang baik cenderung dapat mengurangi keterlibatannya dalam perbuatan kecanduan game online. Idealnya, mahasiswa yang sudah atau sedang menempuh masa perkembangan remaja akhir dapat membatasi diri ketika bermain game online untuk mengontrol frekuensi dan durasi bermain mereka karena salah satu tugas perkembangan mereka yaitu memperkuat self-control (kemampuan mengendalikan diri) atas 
dasar skala nilai, prinsip-prinsip, atau falsafah hidup (Weltanschauung) (Jahja, 2011). Tahap perkembangan remaja akhir menurut Santrock (2011) yaitu remaja yang berusia 18-21 tahun.

Berdasarkan hal tersebut dapat dikatakan bahwa mahasiswa yang sedang menempuh masa remaja akhir sudah memiliki self-control yang tinggi. Namun, remaja juga masih dianggap labil karena masih dalam masa peralihan dari kanak-kanak menjadi dewasa yang memiliki tugas dan tanggung jawab yang lebih kompleks dan masih memiliki tugas dalam pencarian identitas dirinya, serta meningkatkan kemampuan mengendalikan perasaan atau emosinya. Hal tersebut menyebabkan mahasiswa rentan untuk memiliki tingkat self-control yang rendah dikarenakan pada tahap tersebut mahasiswa masih memiliki tugas perkembangan yaitu untuk memperkuat self-control dan identitas dirinya.

Penjelasan yang telah diuraikan sebelumnya membuat peneliti ingin mengetahui lebih lanjut tentang hubungan antara Self-control dengan Online Gaming Addiction pada mahasiswa di Surabaya. Pertanyaan dalam penelitian ini berfokus pada seberapa besar hubungan antara Self-control dengan Online Gaming Addiction pada mahasiswa di Surabaya.

\section{Desain Penelitian}

\section{E T O D E}

Penelitian ini menggunakan desain penelitian kuantitatif korelasional. Penulis menggunakan pendekatan kuantitatif dengan tujuan akan menghasilkan data dalam bentuk angka yang didapatkan dari hasil jawaban partisipan melalui survei atau pertanyaan yang diajukan ke sejumlah besar partisipan berupa kuesioner. Pengumpulan data dilakukan dengan menyebarkan kuesioner atau angket secara online melalui Google Form. Kuesioner dibagi menjadi tiga bagian yaitu data demografis, skala Self-control Scale untuk mengukur tingkat Self-control dan skala Game Addiction Scale untuk mengukur tingkat kecanduan bermain game online. Uji validitas yang digunakan yaitu content validity atau validitas konten dengan bantuan professional judgement. Sedangkan pengukuran reliabilitas menggunakan koefisien Alpha Cronbach. Analisis data yang digunakan yaitu korelasi Pearson's $r$ dengan bantuan program JAMOVI 1.6.6.0 for Windows. Analisis data tersebut dipakai dengan tujuan untuk mengetahui hubungan antara Self-control dengan Online Gaming Addiction pada mahasiswa di Surabaya.

\section{Partisipan}

Partisipan dalam penelitian ini memiliki karakteristik berjenis kelamin laki-laki atau perempuan, berusia 18-21 tahun, Semester 1-7, bermain game online, dan mahasiswa yang berkuliah di Surabaya. Teknik sampling yang digunakan adalah accidental sampling, yaitu pengambilan sampel tidak berdasarkan peluang. Anggota sampel yang diambil tidak direncanakan terlebih dahulu, tetapi didapatkan atau dijumpai secara tiba-tiba (Azwar, 2012), sehingga pemilihan partisipan hanya berdasarkan siapapun yang didapatkan atau dapat dijangkau peneliti, serta sesuai dengan kriteria partisipan penelitian. Dalam memperkirakan jumlah sampel yang akan diteliti, penulis menggunakan software $G^{*}$ Power dengan menggunakan pengaturan Statistical test berupa Correlation: point biserial model two tails dengan Effect size sebesar 0.3, alpha error prob 0.05 dan power 0.8 yang menghasilkan total sampel yang dibutuhkan sebanyak 82 orang. Jumlah partisipan yang terkumpul dengan mengisi form yang telah disediakan yaitu sebanyak 116 partisipan. Sebelum mengisi form tersebut, partisipan diminta untuk membaca pernyataan yang diberikan untuk memastikan bahwa partisipan setuju untuk berpartisipasi dalam penelitian ini.

Untuk menguji hipotesis penelitian, penulis merekrut 116 partisipan dengan gambaran partisipan yaitu laki-laki berjumlah 64 orang (55,2\%), dan perempuan berjumlah 52 orang $(44,8 \%)$. Ada pula gambaran partisipan berdasarkan usia yaitu partisipan yang berusia 18 tahun berjumlah 3 orang (2,6\%), usia 19 
tahun sejumlah 10 orang (8,6\%), usia 20 tahun sejumlah 37 orang (31,9\%), usia 21 tahun sejumlah 66 orang $(56,9 \%)$, kemudian mahasiswa yang sedang menempuh semester 1 sejumlah 7 orang $(6,1 \%)$, semester 3 sejumlah 21 orang (18,1\%), semester 5 sejumlah 23 orang $(19,8 \%)$, dan semester 7 sejumlah 65 orang (56\%).

\section{Pengukuran}

Pengukuran yang dilakukan terkait dengan self-control dalam penelitian ini menggunakan skala pengukuran self-control scale milik Tangney dkk. (2004) yang di translasi dan digunakan dalam penelitian sebelumnya oleh Masyita (2016). Self-control scale dalam penelitian ini digunakan untuk mengukur tingkat self-control dengan total 10 aitem. Skala ini menggunakan 5 kategori pilihan jawaban (1= "tidak pernah", 5= "sangat sering"). Skala ini dibagi menjadi 2 jenis pertanyaan, yaitu favorable dan unfavorable. Sedangkan skala online gaming addiction yang digunakan dalam penelitian ini menggunakan skala gaming addiction scale yang dikembangkan oleh Lemmens dkk. (2009) yang di translasi dan telah digunakan dalam penelitian penelitian sebelumnya oleh Masyita (2016) gaming addiction scale dalam penelitian ini digunakan untuk mengukur tingkat kecanduan bermain game online. Skala ini terdiri dari 21 aitem favorable, dan menggunakan 5 kategori pilihan jawaban berupa skala likert (1="tidak pernah", 5="sangat sering").

Validitas yang digunakan dalam penelitian ini yaitu validitas konten (content validity) dengan bantuan professional judgement yang dianggap memiliki keahlian sesuai dengan bidang penelitian ini. Sedangkan reliabilitas yang digunakan pada penelitian ini berasal dari koefisien Cronbach's alpha., reliabilitas alat ukur self-control scale yang telah penulis peroleh adalah coefficient $\alpha=0,729$ dan reliabilitas untuk alat ukur online gaming addiction yaitu coefficient $\alpha=0,905$.

Skor diperoleh dengan cara dijumlah. Uji asumsi yang dilakukan dalam penelitian ini yaitu uji normalitas untuk mengetahui bahwa data yang didapat berdistribusi normal atau tidak. Uji normalitas dilakukan dengan bantuan JAMOVI 1.6. dengan shapiro wilk, dimana data dikatakan normal apabila hasil diatas 0,05. Data dalam penelitian ini memperoleh skor 0,724 untuk self-control dan 0,070 untuk online gaming addiction, maka data dalam penelitian ini dikatakan berdistribusi normal.

\section{Analisis Data}

Uji korelasi yang dilakukan yaitu menggunakan korelasi Pearson's $r$ dengan bantuan program Jamovi 1.6.6.0 for Windows.

\section{HAS I L P E N EL I T I A N}

Hasil analisis deskriptif menunjukkan jumlah $(N=116)$ partisipan yang dianalisa dari setiap skala. Skor terendah (Min) self-control dari data partisipan sebesar 19 sedangkan nilai tertingginya (Max) 46, dan rata-rata (Mean) sebesar 32. Pada online gaming addiction, nilai terendah (Min) adalah 21, nilai tertingginya (Max) adalah 99, dan rata-rata (Mean) sebesar 54,1. Sebagian besar partisipan penelitian memiliki tingkat self-control kategori sedang, yaitu sebanyak 79 orang $(68,1 \%)$. Sedangkan partisipan penelitian yang memiliki tingkat self-control kategori rendah sebanyak 19 orang (16,4\%), dan partisipan yang memiliki tingkat self-control kategori tinggi sebanyak 18 orang $(15,5 \%)$. Selain itu, sebagian besar partisipan penelitian memiliki tingkat online gaming addiction kategori sedang, yaitu sebanyak 81 orang $(69,8 \%)$. Sedangkan partisipan yang memiliki tingkat online gaming addiction kategori rendah sebanyak 20 orang $(17,24 \%)$. kategori tinggi sebanyak 15 orang $(12,93 \%)$. 
Hasil analisis korelasi diketahui bahwa self-control berkorelasi negatif dan berkekuatan sedang $(\mathrm{r}(116)=-0,386,95 \% \mathrm{CI}[-0,217 ;-0,533], p<.001)$ dengan online gaming addiction .

\section{I S K U S I}

Berdasarkan data demografis yang diperoleh, partisipan penelitian didominasi oleh mahasiswa laki-laki yang bermain game online sebesar 55,2\% dari total 116 partisipan, hal itu disebabkan karena adanya perbedaan aktivitas otak yang terjadi pada laki-laki dan perempuan dalam bermain game online. Reiss (2008) menyebutkan bahwa terdapat perbedaan aktivitas otak di pusat mesocortilimbic pada laki-laki dan perempuan ketika bermain game online, aktivasi otak pada bagian tersebut lebih banyak terjadi pada laki-laki daripada perempuan. Hal tersebut menyebabkan rasa ketagihan pada laki-laki untuk terus bermain game online. Kemudian Sun, dkk. (2018) dalam penelitiannya juga berpendapat bahwa adanya perubahan fungsi otak yang signifikan pada otak di gyrus frontal superior, area lobus prefrontal yang berfungsi untuk mengendalikan impuls daripada pada perempuan ketika bermain game online. Karena adanya perbedaan fungsi otak yang terjadi pada laki-laki dan perempuan ketika bermain game online itulah yang menyebabkan lebih banyaknya jumlah pemain game online laki-laki daripada perempuan.

Uji korelasi menunjukkan adanya hubungan negatif yang signifikan antara kedua variabel penelitian $(r(116)=-0,386,95 \%$ CI $[-0,217 ;-0,533], p<.001)$. Sehingga, dapat disimpulkan bahwa $\mathrm{H}_{\mathrm{o}}$ ditolak $\mathrm{H}_{\mathrm{a}}$ diterima karena menunjukkan adanya hubungan antara variabel self-control dengan variabel online gaming addiction. Namun, kekuatan hubungan yang dihasilkan cenderung berkekuatan sedang. Nilai koefisien korelasi yang negatif sebesar - 0.386 menunjukkan bahwa terdapat hubungan bersifat negatif antara kedua variabel, artinya ketika variabel self-control mengalami kenaikan, maka variabel online gaming addiction mengalami penurunan dan begitupun sebaliknya. Kemudian, angka koefisien korelasi sebesar -0,384 menunjukkan adanya kekuatan hubungan antar variabel yang cenderung sedang.

Hasil penelitian ini selaras dengan penelitian-penelitian yang ada sebelumnya. Mehroof dan Griffith (2010) melalui penelitiannya menunjukkan bahwa adanya hubungan yang negatif antara self-control dengan online gaming addiction yang mana semakin tinggi tingkat self-control maka tingkat online gaming addiction akan semakin rendah. Selain itu, Teng, Li \& Liu (2014) melalui penelitiannya menunjukkan adanya hubungan positif antara online gaming addiction terhadap low self-control, dimana semakin tinggi tingkat low self-control, semakin tinggi pula online gaming addiction pada individu. Selain itu, Masyita (2016) melalui penelitiannya menunjukkan bahwa adanya hubungan negatif yang berkekuatan sedang untuk kontrol diri dengan kecanduan game online yang mana semakin tinggi tingkat self-control maka tingkat online gaming addiction akan semakin rendah. Penelitian lainnya yang dilakukan oleh Mehroof dan Griffith (2010) menunjukkan bahwa terdapat hubungan yang signifikan antara self-control dengan online gaming addiction.

Hasil yang didapat memiliki tingkat korelasi yang sedang, hal itu disebabkan oleh hasil partisipan yang menunjukkan tingkat self-control yang cenderung sedang yang disebabkan karena partisipan dalam penelitian ini sedang menempuh tahapan perkembangan remaja hingga remaja akhir dimana pada tahap perkembangan tersebut remaja cenderung masih labil dan memiliki salah satu tugas perkembangan yaitu untuk mencari jati diri dan Memperkuat self-control (kemampuan mengendalikan diri) atas dasar skala nilai, prinsip-prinsip, atau falsafah hidup (weltanschauung) (Jahja, 2011). Kemudian, hasil partisipan menunjukkan tingkat kecanduan bermain game online yang sedang. Hal itu disebabkan oleh tingkat self-control yang dimiliki partisipan cenderung sedang. Sesuai yang disebutkan oleh Young (2009) bahwa salah satu faktor penyebab dari kecanduan game online adalah lack of control atau ketidakmampuan dalam mengontrol diri yang menyebabkan banyaknya waktu yang digunakan 
untuk bermain game online akan semakin bertambah karena tidak dapat mengatur intensitas bermain game online.

Kemudian, Ghufron \& Risnawita (2010) menyatakan bahwa self-control merupakan kemampuan untuk Menyusun, membimbing, mengatur, dan mengarahkan bentuk perilaku yang dapat membawa individu kearah konsekuensi yang positif. Dalam hal ini mahasiswa yang dapat mengendalikan perilaku serta dorongan-dorongan dari dalam diri mahasiswa untuk secara terus-menerus bermain game online dan mengendalikan emosinya sehingga dapat berpikir secara rasional dan mempertimbangkan risiko yang akan terjadi sehingga mahasiswa akan terbiasa mengendalikannya dan tidak muncul reaksi atau perilaku untuk kecanduan bermain game online. Jadi seharusnya mahasiswa harus bisa membatasi waktu dan intensitas bermainnya sehingga bermain game online tidak menjadi hal yang merugikan yang dapat mengganggu aspek-aspek kehidupannya atau tanggung jawab lainnya.

\section{S I M P U L A N}

Hasil dari penelitian ini menunjukkan bahwa terdapat hubungan antara self-control dengan online gaming addiction dengan kekuatan hubungan sedang dan negatif, memiliki hubungan yang sedang karena subjek sedang memasuki tahap perkembangan remaja hingga remaja akhir dimana remaja biasanya masih labil. Kemudian, salah satu tugas perkembangannya adalah mencari jati diri dan meningkatkan self-control. Memiliki hubungan negatif karena self-control berperan dalam mengurangi tingkat online gaming addiction. Sehingga apabila individu memiliki tingkat self-control yang tinggi maka tingkat online gaming addiction individu tersebut rendah begitupun sebaliknya.

Saran untuk orang tua mahasiswa agar anaknya tidak kecanduan bermain game online yaitu meningkatkan kualitas komunikasi pada anak, menambah perhatian pada anak, dan menyelesaikan konflik yang terjadi pada keluarga. Saran tersebut bertujuan agar mahasiswa tidak terlalu menghabiskan waktu luangnya untuk bermain game online sehingga tidak kecanduan bermain game online. Selanjutnya, saran untuk mahasiswa yaitu melakukan self-management terhadap waktu seperti membuat jadwal kegiatan sehari-hari, menentukan prioritas, menyeimbangkan kegiatan belajar, bersenang-senang, dan bersantai (Elvina, 2019). Hal tersebut dilakukan agar mahasiswa dapat lebih mengatur kebiasaannya dan mengarahkan kegiatannya kearah yang lebih positif agar tidak kecanduan game online. Saran untuk penelitian selanjutnya yaitu dapat dilakukan di daerah lain untuk mendapat variasi data yang berbeda.

\section{U C A P A N T E R I MA K A S I H}

Terima kasih saya ucapkan kepada Allah SWT, keluarga, dosen pembimbing dan teman-teman yang telah mendukung dan membantu penulis selama proses penelitian. Terima kasih juga saya ucapkan kepada peneliti sebelumnya yang telah memberikan izin untuk pemakaian alat ukur self-control scale dan game addiction scale.

\section{DEKLARASI POTENSI TERJADINYAKONFLIK KEPENTINGAN}

Wira Adi Cahyo Wibowo dan Afif Kurniawan tidak bekerja, menjadi konsultan, memiliki saham, atau menerima dana dari perusahaan atau organisasi manapun yang mungkin akan mengambil untung dari diterbitkannya naskah ini. 


\section{PUSTAKA ACUAN}

Antara Jatim. (2018). Survei: Gamers Surabaya Habiskan 2-8 Jam Sehari. Diakses dari Antara News Jatim: https://jatim.antaranews.com/berita/200839/survei-gamers-surabaya-habiskan-2-8-jamsehari

Azwar, S. (2012). Metode Penelitian. Yogyakarta: Pustaka Pelajar.

Chen, C. Y., \& Chang, S. L. (2008). An Exploration of the Tendency to Online Game Addiction Due to User's Liking of Design Features. Asian Journal of Health and Information Sciences, 38-51.

D.M., E. R. (2019). Perilaku Adiksi Remaja Pada Game Online di Surabaya. Fisip Unair, 1-10.

Daldiyono. (2009). How to be a Real and Succesful Student. Jakarta: Gramedia Pustaka Utama.

detiknews. (2018). Fenomena Warung Kopi di Surabaya dan Kisah Para Pemburu Wifi. Diakses dari detiknews: https://news.detik.com/berita-jawa-timur/d-3938889/fenomena-warung-kopi-disurabaya-dan-kisah-para-pemburu-wifi

Elvina, S. N. (2019). Teknik Self Management dalam Pengelolaan Strategi Waktu Kehidupan Pribadi yang Efektif. Islamic Counseling: Jurnal Bimbingan dan Konseling Islam, 123-128.

Ghufron, M. N., \& Risnawita, R. S. (2010). Teori-teori psikologi. Jogjakarta: Ar-Ruzz Media.

Ismail, A., \& Zawahreh, N. (2017). Self Control and Its Relationship With the Internet Addiction Among a Sample of Najran University Students. Journal of Education and Human Development, 186-174.

Jahja, Y. (2011). Psikologi Perkembangan. Jakarta: Kencana.

Lemmens, J. S., Valkenburg, P. M., \& Peter, J. (2009). Development and validation of a game addiction scale for adolescent. Media Psychology, 12(1), 75-95. doi:10.1080/15213260802669458

Marketeers. (2019). Rata-rata Gamer Habiskan 7,5 Jam Per Minggu Untuk Main Game. Diakses dari Marketeers: https://marketeers.com/rata-rata-gamer-habiskan-75-jam-per-minggu-untukmain-game/

Masya, H., \& Candra, D. (2016). Faktor-faktor yang mempengaruhi perilaku gangguan kecanduan game online pada peserta didik kelas X madrasah aliyah Al Furqon Prabumulih tahun pelajaran 2015/2016. Jurnal Bimbingan dan Konseling, 03(1), 153-169.

Masyita, A. R. (2016). Pengaruh Kontrol Diri Terhadap Kecanduan Game Online Pada Pemain Dota 2 Malang. Malang: Universitas Islam Negeri Maulana Malik Ibrahim .

Maulida, L. (2018). Jumlah Gamer di Indonesia Capai 100 Juta di 2020. Diakses dari tek.id: https://www.tek.id/insight/jumlah-gamer-di-indonesia-capai-100-juta-di-2020-

b1U7v9c4A\#: :text=akan\%20meningkat\%20signifikan.-

,Pokkt\%2C\%20Decision\%20Lab\%20dan\%20Mobile\%20Marketing\%20Association\%20(MMA )\%20yang,menjadi\%20100\%20juta\%20pada\%202020.

Mehroof, M., \& Griffith, M. D. (2010). Online Gaming Addiction: The Role of Sensation Seeking, Self Control, Neuroticism, Aggression, State Anxiety, and Trait Anxiety. Journal Cyberpsychology, Behaviour, and Social Networking, 3. 
Puspita, S. T., \& Mulyana, O. P. (2018). Hubungan Antara Kontrol Diri Dengan Kecanduan Game Online Pada Remaja Akhir. Journal Psikologi Pendidikan.

Reiss, A. L., Hoeft, F., Watson, C. L., Kesler, S. R., \& Bettinger, K. E. (2008). Gender Differences in the Mesocortilimbic system during computer game-play. Journal of Psychiatric Research, 253-258.

Rooij, A. J. (2011). Online Video Games Addiction. Exploring A New Phenomenon. Rotterdam: the Netherlands: Erasmus University.

Santrock, J. W. (2011). Life-Span Development thirteen edition. Dallas: McGraw-Hill Companies Inc.

Sun, Y., Wang, Y., Han, X., Jiang, W., Ding, W., Cao, M., Zhou, Y. (2018). Sex Differences in Resting-State Cerebral Activity Alterations in Internet Gaming Disorder. Brain Imaging and Behaviour, 14061417.

Tangney, J., Baumeister, R. F., \& Boone, F. (2004). High self-control predicts good adjustment, Less pathology, Better grades, And interpersonal success. Journal of Personality, 72(2).

Teng, Z., Li, Y., \& Liu, Y. (2014). Online Gaming, Internet Addiction, and Aggression of Chinese Male students: The Mediating Role of Low Self-Control. International Journal of Psychological Studies, 89-97.

Young, K. (2009, September 11). Understanding Online Gaming Addictions and Treatment Issues for Adolescents. The American Journal of Family Therapy, 37:5,355-372. doi:10.1080/01926180902942191 